\title{
Pengaruh Promosi Melalui Instagram dan Event terhadap Repurchase Intention do Cenghar Kopi Kota
}

\author{
Gita Siswhara ${ }^{1}$, Masharyono ${ }^{2}$, Dian Anggraeny ${ }^{3}$ \\ ${ }^{1}$ Manajemen Industri Katering, Fakultas Pendidikan Ilmu Pengetahuan Sosial, Universitas \\ Pendidikan Indonesia, Jl. Dr. Setiabudhi No. 229, Bandung 40154, Indonesia \\ ${ }^{2}$ Manajemen Bisnis, Fakultas Pendidikan Ekonomi dan Bisnis, Universitas Pendidikan \\ Indonesia, Jl. Dr. Setiabudhi No. 229, Bandung 40154, Indonesia \\ ${ }^{3}$ Manajemen Industri Katering, Fakultas Pendidikan Ilmu Pengetahuan Sosial, \\ Universitas Pendidikan Indonesia, Jl. Dr. Setiabudhi No. 229, Bandung 40154, Indonesia \\ * Koresponding Penulis. E-mail: gitasiswhara@student.upi.edu (Gita Siswhara)
}

\begin{abstract}
Abstrak
Penelitian ini berfokus pada pengaruh promosi melalui instagram dan event terhadap repurchase intention di Cenghar Kopi Kota Cimahi. Permasalahan yang terjadi dalam penelitian ini adalah pendapatan yang fluktuatif namun cenderung menurun dari bulan ke bulannya. Tujuan dari penelitian ini adalah untuk mengetahui pengaruh dari promosi melalui instagram dan event yang di lakukan oleh Cenghar Kopi terhadap repurchase intention pada konsumen. Metode yang digunakan dalam penelitian adalah explanatory survey dengan sampel yang berasal dari populasi konsumen Cenghar Kopi Cimahi. Berdasarkan penelitian yang dilakukan, didapatkan hasil yang menunjukkan bahwa promosi melalui instagram dan event berpengaruh positif dan signifikan terhadap repurchase intention baik secara parsial maupun simultan. Saran dalam penelitian ini adalah repurchase intention dapat ditingkatkan jika manajemen memperbaharui promosi yang dilakukan, dengan lebih kreatif dan inovatif. Sehingga repurchase intention lebih banyak dilakukan di Cenghar Kopi Kota Cimahi.
\end{abstract}

Kata Kunci: Promosi, Instagram, Event, dan Repurchase Intention

\section{Pendahuluan}

Indonesia merupakan salah satu negara yang dapat menjadi tujuan wisata, karena selain memiliki kekayaan budaya juga memiliki kekayaan alam yang melimpah ruah. Salah satu tujuan wisata adalah Jawa Barat merupakan salah satu provinsi yang memiliki keanekaragaman daya tarik wisata yang cukup tinggi, baik dari wisata alam, budaya, dan buatan. Hal tersebut memberikan motivasi pada para wisatawan untuk datang ke Jawa Barat.

Salah satu kota di Jawa Barat yang memiliki daya tarik untuk dikunjungi wisatawan adalah kota Cimahi. Kota Cimahi merupakan salah satu kota yang difokuskan menjadi pusat wisata militer. Selain menjadi kota wisata militer, Kota Cimahi mengandalkan alam yang ada, kemudian Kota Cimahi menjadi kota wisata alam (Wanjat, dkk, 2016: 36). Dengan diawali menjadi salah satu Kota dari 90 Kabupaten/Kota yang ditunjuk oleh Kementerian Pariwisata untuk menggelar acara Sadar Wisata dan Aksi Sapta Pesona.

Kini kota Cimahi tidak hanya berfokus pada wisata militer, tetapi juga berfokus pada wisata kuliner, industri tekstil, garmen temasuk produksi batik, pengembangan teknologi telematika dan animasi.

Restoran merupakan salah satu aspek pendukung dari wisata. Sama seperti yang dikatakan oleh Sparks, Bowen, \& Klag (2003: 2) "restaurants are an 
important factor in the choice of a holiday destination for some tourists" bahwa restaurant juga salah satu faktor penting yang dipilih oleh wisatawan dalam tujuan liburannya.

Pendapatan Cenghar Kopi mengalami penurunan di bulan Januari 2017 sebesar 16.390.090 Hal itu disebabkan karena adanya perubahan infrakstuktur Café. Namun setelah café berjalan pendapatan kembali naik namun bergerak fluktuatif cenderung turun, sedangkan harapan owner dan tim marketing Cenghar Kopi pendapatan Cenghar Kopi terus bergerak naik ke atas.

Penurunan pendapatan yang terjadi dikarenakan kurangnya minat konsumen untuk melakukan repurchase intention, hal ini disampaikan oleh owner Cenghar Kopi Bapak Ridwan pada tanggal 2 Penurunan pendapatan yang terjadi dikarenakan kurangnya minat konsumen untuk melakukan repurchase intention, hal ini disampaikan oleh owner Cenghar Kopi Bapak Ridwan pada tanggal 2 Juni 2017 pukul 20.00 dengan terlihatnya konsumen yang baru namun tidak banyak yang kembali mengunjungi Cenghar Kopi untuk melakukan repurchase intention.

Repurchase intention dipengaruhi oleh promosi seperti yang disampaikan oleh Kotler \& Amstrong (2012: 221) jika salah satu tujuan promosi adalah reminding (mengingatkan) pada konsumen terhadap merek perusahaan. Banyak promosi yang dapat dilakukan namun diantaranya adalah instagram dan event. Instagram menjadi sarana yang tepat untuk media promosi masa kini, dimana promosi yang dilakukan melalui jalinan komunikasi secara langsung pada konsumen, sehingga konsumen secara tidak langsung akan selalu mengingat merek perusahaan (Gumgum, 2015: 79).

Event juga salah satu media promosi yang dilakukan Cenghar Kopi, fungsi event dalam promosi adalah sebagai daya tarik perusahaan dan sebagai pembentuk citra positif perusahaan pada konsumen (Blythe, 2013: 191). Perusahaan perlu memperhatikan berbagai hal yang ikut mempengaruhi keberhasilan dalam pelaksanaan promosi dalam strategi promosi. Hal yang perlu diperhatikan adalah bauran promosi (promotional mix) terdiri dari beberapa variabel utama diantaranya adalah periklanan (advertising), penjualan pribadi (personal selling), promosi penjualan (sales promotion), dan publisitas (publicity). Agar promosi yang dilakukan dapat terlaksana dengan baik, maka perusahaan harus mempelajari adaptasi potensial yang paling cocok terhadap kondisi perusahaan maupun konsumen baik secara internal maupun eksternal (Siti, $2015: 55)$.

Menurut Kotler dan Keller (2016: 155) mengemukakan bahwa:

"Perusahaan selain harus mendapatkan pelanggan sebanyakbanyaknya, perusahaan juga harus dapat mempertahankan kesetiaan pelanggannya agar dapat bertahan dalam bisnis ini. Salah stau upaya mempertahankan pelanggan yang telah ada dengan menarik pelanggannya untuk melakukan pembelian ulang".

Maka dari itu untuk meningkatkan minat beli ulang harus membuat konsumen mengingat kembali perusahaan dengan melakukan promosi. Promosi yang dilakukan oleh Cenghar Kopi adalah dengan menggunakan instagram dan event. Pemilihan instagram sebagai media promosi berdasarkan dari kepopuleran instagram dalam menyebarkan foto dan membuat pelaku usaha mudah untuk mempromosikan produknya (M Nisrina, 2015: 137). Menurut Tiawarma dan Rendy (2013: 1) event yang baik, mempunyai product display yang juga menarik, tetapi juga kreativitas special event yang menarik, seperti : lomba, demo produk yang didukung pula dengan pemasangan spanduk, poster, brosur, yang bisa melibatkan konsumen secara interaktif. Dan pemilihan event sebagai promosi di Cenghar Kopi adalah event musik sebagai atraksi penarik konsumen untuk datang ke Cenghar 
Kopi.

Penelitian ini dilakukan pada Cenghar Kopi yang berada di jalan Ciawitali No. 42, Cimahi. Penelitian dilakukan berdasarkan terjadinya pendapatan yang fluktuatif cederung menurun di Cenghar Kopi.

Tujuan melakukan penelitian ini adalah sebagai berikut:

a. Mengetahui gambaran promosi melalui Instagram yang dilakukan di Cenghar Kopi

b. Mengetahui gambaran promosi melalui Event yang dilakukan di Cenghar Kopi

c. Mengetahui gambaran repurchase intention di Cenghar Kopi

d. Mengetahui besarnya pengaruh promosi melalui Instagram terhadap repuchase intention di Cenghar Kopi.

e. Mengetahui besarnya pengaruh promosi melalui event terhadap repuchase intention di Cenghar Kopi.

f. Mengetahui besarnya pengaruh promosi melalui Instagram dan Event terhadap repurchase intention di Cenghar Kopi.

\section{Metode Penelitian}

Objek yang dijadikan responden dalam penelitian ini adalah konsumen Cenghar Kopi. Penelitian ini menggunakan dua jenis penelitian, yaitu deskriptif dan verifikatif. Dalam penelitan ini akan diuji apakah promosi melalui instagram dan event berpengaruh terhadap repurchase intention di Cenghar Kopi. Adapun sumber data dalam peelitian ini yaitu primer (internet, data Cenghar Kopi) dan sekunder (Dinas). Adapun dalam penelitian ini, yang menjadi populasi adalah seluruh konsumen yang telah memfollow instagram dan pernah datang ke event yang diadakan Cenghar Kopi dengan jumlah 4.812 orang. Teknik sampling yang digunakan pada penelitian ini adalah purposive sampling. Teknik analisis data yang digunakan yaitu regresi linier berganda. Hipotesis yang diuji dalam penelitian ini adalah mengenai ada atau tidak adanya pengaruh antara variabel yang diteliti, yaitu variabel yang diangkat antara variabel bebas tentang promosi melalui instagram $\left(\mathrm{X}_{1}\right)$ dan promosi melalui event $\left(\mathrm{X}_{2}\right)$ terhadap variabel terikat yaitu repurchase intention $(\mathrm{Y})$. Sehingga hipotesis dalam penelitian ini sebagi berikut:

$$
\text { 1. Hipotesis } 1
$$

$\mathrm{Ho}=$ artinya tidak terdapat pengaruh positif dari Instagram terhadap repurchase intention.

$\mathrm{Ha}=$ artinyaa terdapat pengaruh positif dari instagram terhadap repurchase intention.

2. Hipotesis 2

Ho $=$ artinya tidak terdapat pengaruh positif dari event terhadap repurchase intention.

$\mathrm{Ha}=$ artinya terdapat pengaruh positif dari event terhadap repurchase intention.

3. Hipotesis 3

$\mathrm{Ho}=$ artinya tidak terdapat pengaruh positif dari Instagram dan event terhadap repurchase intention

$\mathrm{Ha}=$ artinya terdapat pengaruh positif dari instagram dan event terhadap repurchase intention

Di mana, jika $\mathrm{F}_{\text {hitung }}>\mathrm{F}_{\text {tabel }}$ maka Ho ditolak dan Ha diterima.

\section{Hasil dan Pembahasan}

3.1. Tanggapan Responden Terhadap Minat Meneruskan Pembelian Ulang

Berdasarkan hasil pengolahan data yang dilakukan melalui penyebaran kuisioner pada konsumen Cenghar Kopi Cimahi, Instagram dapat diukur melalui perhitungan rata-rata dimensi dan perhitungan skor keseluruhan. Berikut ini dipaparkan hasil dari rekapitulasi perhitungan skor.

Tabel 1. Rekapitulasi Variabel Instagram pada Konsumen Cenghar Kopi

\begin{tabular}{llccc}
\hline No. & Dimensi & $\begin{array}{c}\text { Total } \\
\text { Skor }\end{array}$ & $\begin{array}{c}\text { Skor } \\
\text { Ideal }\end{array}$ & $\begin{array}{c}\text { Persentase } \\
(\%)\end{array}$ \\
\hline 1. & Hastag & 524 & 700 & $75 \%$ \\
2. & Geotag & 506 & 700 & $72 \%$ \\
3. & Follow & 931 & 1400 & $67 \%$ \\
4. & Share & 421 & 700 & $66 \%$ \\
5. & Like & 459 & 700 & $66 \%$
\end{tabular}




\begin{tabular}{llccc}
\hline No. & Dimensi & $\begin{array}{c}\text { Total } \\
\text { Skor }\end{array}$ & $\begin{array}{c}\text { Skor } \\
\text { Ideal }\end{array}$ & $\begin{array}{c}\text { Persentase } \\
(\%)\end{array}$ \\
\hline 6. & Comment & 515 & 700 & $74 \%$ \\
7. & Mention & 858 & 1400 & $61 \%$ \\
& Total & 4214 & 6300 & $61 \%$ \\
\hline
\end{tabular}

Sumber : Data diolah, 2017

Berdasarkan Tabel 1 aspek Instagram paling tinggi yaitu terdapat pada dimensi hastag memperoleh skor sebanyak 524 atau $75 \%$, sementara dimensi share hanya mendapat skor 421 atau $60 \%$. Secara keseluruhan variabel Instagram memperoleh skor 4214. Apabila di persentasekan ke dalam skor ideal maka diperoleh persentase sebesar $61 \%$, dapat dikatakan bahwa hampir seluruh konsumen menyatakan bahwa Instagram sebagai media promosi di Cenghar Kopi Cimahi dalam kategori cukup efektif. Dimana dari promosi yang dilakukan melalui instagram dapat menarik minat beli ulang di Cenghar Kopi, seperti yang disampaikan oleh Natasia, Elisabeth \& Regina (2015: 358) bahwa komunikasi pemasaran yang efektif memiliki peran yang penting dalam menjalankan proses promosi berawal dari awarness, knowledge, liking, preference, conviction hingga terjadinya purchase.

\subsection{Rekapitulasi Variabel Event Pada}

Konsumen Cenghar Kopi

Berdasarkan hasil pengolahan data yang dilakukan melalui penyebaran kuisioner pada konsumen Cenghar Kopi Cimahi, Event dapat diukur melalui perhitungan rata-rata dimensi dan perhitungan skor keseluruhan. Berikut ini dipaparkan hasil dari rekapitulasi perhitungan skor.

Tabel 2. Rekapitulasi Tanggapan Responden terhadap Implicit

\begin{tabular}{llccc}
\hline No. & Dimensi & $\begin{array}{c}\text { Total } \\
\text { Skor }\end{array}$ & $\begin{array}{c}\text { Skor } \\
\text { Ideal }\end{array}$ & $(\%)$ \\
\hline 1. & Relevant & 541 & 700 & $77 \%$ \\
2. & Engaging & 1590 & 2100 & $78 \%$ \\
3. & Implicit & 1026 & 1400 & $73 \%$ \\
& Total & 3157 & 4200 & $75 \%$ \\
\hline
\end{tabular}

Sumber : Data diolah, 2017
3.3. Variabel Repurchase Intention Pada Konsumen Cenghar Kopi

Berdasarkan hasil pengolahan data yang dilakukan melalui penyebaran kuisioner pada konsumen Cenghar Kopi Cimahi, Event dapat diukur melalui perhitungan rata-rata dimensi dan perhitungan skor keseluruhan. Berikut ini dipaparkan hasil dari rekapitulasi perhitungan skor.

Tabel 3. Rekapitulasi Variabel Repurchase Intention pada Konsumen Cenghar Kopi

\begin{tabular}{llccc}
\hline No & \multicolumn{1}{c}{ Dimensi } & $\begin{array}{c}\text { Total } \\
\text { Skor }\end{array}$ & $\begin{array}{c}\text { Skor } \\
\text { Ideal }\end{array}$ & $(\%)$ \\
\hline 1. & $\begin{array}{l}\text { Intensitas } \\
\text { Pembelian }\end{array}$ & 1612 & 2100 & $77 \%$ \\
2. & $\begin{array}{l}\text { Kuantitas } \\
\text { Pembelian }\end{array}$ & 1008 & 1400 & $72 \%$ \\
3. $\begin{array}{l}\text { Minat } \\
\text { Meneruskan } \\
\text { Pembelian } \\
\text { Total }\end{array}$ & 1462 & 2100 & $70 \%$ \\
\hline
\end{tabular}

Sumber : Data diolah, 2017
Untuk mengetahui hubungan fungsional secara linear antara kedua varibel dilakukan pengujian regresi berganda. Regresi juga digunakan untuk mengetahui seberapa besar pengaruh kualitas produk terhadap kepuasan konsumen. Berdasarkan hasil pengolahan data denganbantuan SPSS for windows, hasilnya sebagai berikut:

Tabel 4. Hasil Pengujian Regresi Berganda

\begin{tabular}{|c|c|c|c|c|c|c|c|}
\hline & & \multicolumn{2}{|c|}{$\begin{array}{l}\text { Unstandardized } \\
\text { Coefficients }\end{array}$} & $\begin{array}{l}\text { Standardi } \\
\text { zed } \\
\text { Coefficie } \\
\text { nts }\end{array}$ & \multirow[t]{2}{*}{$\mathrm{T}$} & \multicolumn{2}{|c|}{ Sig. } \\
\hline & & B & $\begin{array}{l}\text { Std. } \\
\text { Error }\end{array}$ & Beta & & & \\
\hline \multirow[t]{5}{*}{1} & \multirow{2}{*}{\multicolumn{2}{|c|}{ (Constant) }} & & 1.49 & & 3.16 & .00 \\
\hline & & & 4.141 & 7 & & 8 & 2 \\
\hline & \multirow{3}{*}{\multicolumn{2}{|c|}{$\begin{array}{l}\text { INSTAGR } \\
\text { AM } \\
\text { EVENT }\end{array}$}} & & 046 & 423 & 7.27 & .00 \\
\hline & & & .356 & .040 & .423 & 3 & 0 \\
\hline & & & .695 & .071 & .566 & $\begin{array}{r}9.73 \\
6\end{array}$ & $\begin{array}{r}.00 \\
0\end{array}$ \\
\hline
\end{tabular}

a. Dependent Variable: REPURCHASE INTENTION

Sumber : Data diolah, 2017

Berdasarkan Tabel 4 di atas yang diperoleh dari hasil uji regresi maka estimasi fungsi regresi berganda yang diperoleh adalah : 
$\mathrm{Y}=4,741+0,423 \mathrm{X}_{1}+0,566 \mathrm{X}_{2}$

Berdasarkan persamaan regresi linier berganda diatas, angka-angka yang tertera pada persamaan tersebut menyatakan bahwa jika tidak ada promosi melalu instagram dan event $\left(\mathrm{X}_{1}\right.$ dan $\left.\mathrm{X}_{2}=0\right)$ maka repurchase intention bernilai 4,741 satu satuan nilai.

Setelah itu dapat diketahui thitung melalui uji $\mathrm{t}$ atau ttabel, penentuan $\mathrm{t}$ tabel dilakukan dengan tingkat signifikansi 5\% atau 0,05 pada uji satu pihak dengan derajat kebebasan $(\mathrm{df}=\mathrm{n}-\mathrm{k}, 100-2=98)$ maka didapat ttabel sebesar sebesar 1,664.

$\mathrm{X}_{1}=7,273>1,669$ maka dapat disimpulkan Ho ditolak dan Ha diterima

$\mathrm{X}_{2}=9,736>1,669$ maka dapat disimpulkan Ho ditolak Ha diterima.

Untuk mengetahui besarnya pengaruh variabel $\mathrm{X}$ terhadap $\mathrm{Y}$, maka digunakan koefisien determinasi sebagai berikut:

$$
\begin{aligned}
\mathrm{KD} & =r^{2} \times 100 \% \\
& =(0.857)^{2} \times 100 \% \\
& =0,734449 \times 100 \% \\
& =73,5 \%
\end{aligned}
$$

Nilai $R$-Square menunjukan sebesar 0,735, hasil ini menunjukkan bahwa instagram dan event mampu menjelaskan perubahan yang terjadi pada repurchase intention sebesar $73,5 \%$ dan sisanya $36,5 \%$ dipengaruhi oleh faktor lain yang tidak diteliti dalam penelitian ini.

Pengujian hipotesis dilakukan dengan membandingkan nilai $\mathrm{F}$, jika Fhitung $>$ Ftabel maka H0 ditolak dan Ha diterima. Ftabel dengan derajat keabsahan 0,05 adalah sebesar 3,09. Dengan demikian Fhitung $(313,311)>$ Ftabel $(3,09)$, maka kesimpulanya adalah $\mathrm{H} 0$ ditolak dan $\mathrm{Ha}$ diterima, artinya terdapat pengaruh yang signifikan secara bersama-sama (simultan) dari promosi melalui instagram dan event terhadap repurchase intention di Cenghar Kopi.

\section{Kesimpulan}

Berdasarkan hasil penelitian dapat disimpulkan yaitu promosi melalui instagram dan event di Cenghar Kopi cukup baik. Hal tersebut telah dibuktikan melalui pengolahan data dari pengaruh promosi melalui instagram dan event. Adapun promosi melalui instagram dan event akan berpengaruh terhadap repurchase intention Cenghar Kopi sebesar 73,5\% sedangkan sisanya sebesar $26,5 \%$ dipengaruhi oleh faktor lain seperti kualitas pelayanan, kualitas produk, dan lain-lain.

\section{Daftar Rujukan}

Alexander, D. B. (2014). Analisa Pengaruh Citra Merek (Brand Image) Dan Kepercayaan Merek (Brand Trust) Terhadap Loyalitas Merek (Brand Loyality) ADES Pt. Ades Alfindo Putra Setia. Jurnal Manajemen Pemasaran Petra Vol 1 No.1, 1-9.

Arief, A. R. (2005). Pengantar Perhotelan Dan Restoran. Yogyakarta: Graha Ilmu.

Atmoko, B. D. (2012). Instagram Handbook. Jakarta: Media Kita.

Blythe, J. (2013) Consumer Behaviour. Yogyakarta: Andi

Budi, F. (2010). Pengaruh Harga, Lokasi Dan Promosi Terhadap Minat Pembelian Ulang Pada Supermarket Glora Jl. AR Hakim Medan. Research Gate, 2454.

Cimahi, B. (2014). Statistik Daerah Kota Cimahi Tahun 2015. Cimahi: Badan Pusat Statistik Kota Cimahi.

Cimahi, L. K. (2014). Lakip Kota Cimahi Tahun 2014. Cimahi: Pemerintah Kota Cimahi.

Dedy, Y. (2009). Pengaruh Lokasi Dan Promosi Terhadap Minat Pembelian Ulang Pada Supermarket Madinah Syariah Plaza Millenium Medan. Jurnal Ekonimi USU, 16-37.

Demartoto, A. (2014). Habitus Pengembangan Pariwisata: Konsep Dan Aplikasi. Surakarta, Jawa Tengah: UPT. Penerbitan Dan Pencetakan 
UNS.

Eka, A. S., \& Zakiyah, Z. (2017). The Effect Of Promotion Via Social Media On Repurchase Intention Mediated Electronic Word Of Mouth. Jurnal Ilmu Manajemen Universitas Tadulako , 2443-1850.

Endang, L. W., Idha, H., \& Surip, M. (2009). Konsumsi Kopi Masyarakat Perkotaan Dan Faktor-Faktor Pengaruh: Kasus Di Kabupaten Jember. Jurnal Peloita Perkebunan , 119-231.

Faradiba, \& Tri Astuti, S. R. (2013). Analisis Pengaruh Kualitas Produk, Harga, Lokasi Dan Kualitas Pelayanan Terhadap Minat Beli Ulang Konsumen (Studi Pada Warung Makan "Bebek Gendut" Semarang). Diponegoro Journal Of Management, 1-11.

Fitri, M. (2014). Pengaruh Periklanan, Promosi Penjualan Dan Hubungan Masyarakat Terhadap Keputusan Menabung Di PT. Bank Negara Indonesia, Tbk. Bukit Tinggi. Jurnal Ekonomi UNP , 1-8.

Gersom, H., \& Sugiono, S. (2013). Analisa Pengaruh Experiential Marketing Terhadap Minat Beli Ulang Konsumen Cafe Buntos 99 Sidoarjo. Jurnal Manajemen Pemasaran Vol. 1, No. $2,1-8$.

Getz, D. (2007). Event Tourism: Definition, Evolution And Research. Elsevier, 403-428.

Ghozali. (2013). Aplikasi Analisis Multivariate Dengan Program IBM. SPSS 21 Update. Jakarta: LPES.

Gita, P. (2016). Efektifitas Media Sosial Instagram Sebagai Media Promosi Produk Olahan Pertanian "Yohurt Cimory". VIDIPI, 24-31.

Gita, P. (2016). Efektivitas Media Sosial Instagram Sebagai Media Promosi. Journal IPB , 1-19.

Gumgum, G. (2015). Pemanfaataninstagram Sebagai Sarana Promosi Oleh Pengelola Industri Kreatif Fashion Di
Kota Bandung. Jurnal Ilmu Politik Dan Komunikasi , 68-79.

Hafidz, K. (2015). Efektifitas Media Sosial Instagram Sebagai Media Promosi Batik Solo "INASINUL". IPB JOURNAL , 1-34.

Hamed, M., \& Farideddin, A. H. (2016). Effects Of Promotion On Perceived Quality And Repurchase Intention. International Journal of Scientific Management And Development, 457461.

Hellier, P., Geursen, G., Carr, R., \& Rickard, J. (2003). Customer Repurchase Intention A General Structural Equation Model. European Journal Of Marketing , 1762-1800.

Hui, S., Saebum, K., \& Eun Ju, H. (2016). What Attracts Chinese Customers To Repurchase Korean Cosmetics? Advanced Science And Technology Letters , 55-60.

Indonesia, K. P. (2014). Panduan Optimalisasi Media Sosial Untuk Kementerian Perdagangan RI. Jakarta: Kemendag, RI.

Iuan, Y. L., Chih, Y. Y., Sheng, C. C., \& Chen, J. T. (N.D.). The Study Of Repurchase Intention In Sense Of Experiential Marketing. Research Hipotesis .

Johanna, M. (2006). Analisis Faktor-Faktor Yang Mempengaruhi Minat Beli Ulang. Universitas Diponegoro , 2230 .

Johar, S. (2014). Pemanfaatan-MediaSosial-Instagram-Sebagai-WadahPemasaran-Yang-Efektif. Jurnal UIN, 17-28.

Kotler, P., \& Amstrong, G. (2012). Prinsip Prinsip Pemasaran Edisi.13 Jilid.1. Jakarta: Erlangga.

Kotler, P., \& Keller, K. L. (2016). Marketing Management 16 Edition. New Jersey: Pearson.

Laksana, A., \& Rixikiantono, R. (Jurnal Teknik Pomits Vol. 1, No. 1, (2013) 1-). Perancangan Promosi Event Pekan Budaya Dan Pariwisata Kediri 
2013. $2013,1-7$.

Laurensia, H. P. (2016). Faktor-Faktor Yang Mempengaruhi Minat Pembelian Ulang Konsumen Terhadap Produk Naget Delicy. Performa: Jurnal Manajemen Dan Start-Up Bisnis Vol 1 No2 , 162-170.

Lontoh, M. N. (2016). Analisis Pengaruh Bauran Promosi Terhadap Keputusan Pembelian Mobil Toyota Pada PT. Hasjrat Abadi Manado Cabang Tandean. Jurnal Berkala Ilmiah Efisiensi, 210-220.

Masharyono, \& Cita, U. H. (2016). Pengaruh Kualiatas Produk Terhadap Kepuasan Konsumen Pada Celdi Katering (Survei Pada Konsumen Celdi Katering). Jurnal Manajemen Bisnis, Vol 1, No. 2 , 152-166.

Mikaristhi, T., Yulianti, R. P., \& Nur, A. (2016). Strategi Promosi Coffee Shop Melalui Media Sosial Instagram (Studi Deskriptif Pada Akun (a)Crematology). E-Proceeding Of Management: Vol.3 No.2 , 2421-2432.

Muhammad, F. R., \& Hanifa, Y. (2014). Pengaruh Promosi Dan Harga Terhadap Minat Beli Perumahan Obama Pt. Nailah Adi Kurnia Sei Mencirim Medan. Journal Manajemen Dan Bisnis Vol. 14 , 135143.

Natasia, B. A., Elisabeth, J. P., \& Regina, J. (2015). Analisa Efektifitas Komunikasi Pemasaran Efektif Melalu Instagram Menggunakan Customer Response Indeks (Studi Pada Cafe DE Mandailing Di Surabaya). Jurnal Manajemen Perhotelan, 356-367.

Nisrina, M. (2015). Bisnis Online, Manfaat Media Sosial Dalam Meraup Uang. Yogyakarta: Kobis.

Noor, A. (2009). Manajemen Event. Bandung: C. Alfabeta.

Nova, F. (2009). Crisis Public Relation (Bagaimana PR Menangani Krisis Perusahaan). Jakarta: Grasindo.

Novia, I. S. (2013). Penggunaan Media
Sosial Sebagai Sarana Komunikasi Bagi Komunitas (Studi Deskriptif Kuantitatif Penggunaan Media Sosial Twitter, Facebook Dan Blog Sebagai Sarana Komunikasi Bagi Komunitas Akademi Berbagi Surakarta). Jurnal Komunikasi , 1-16.

Nurul, W. (Jurnal Unesa). Event Sebagai Ajang Promosi Bagi Perusahan Jasa (Kasus Untung Beliung Britama Bri). 2015, 21-31.

Oki, R. F. (2013). Gaya Hidup Santai Mahasiswa (Studi Pada Mahasiswa Universitas Negeri Penikmat Coffee Shop Di Starbuck Coffee). Jurnal Sosial Dan Politik, 1-12.

Putri, N., Haryono, A., \& Mukeri, W. (2016). Efektifitas Atmospher Dan Event Terhadap Keputusan Pembelian Yang Dimediasi Oleh Minat Beli Ulang Pada Konsumen Tembi Rumah Budaya Yogyakarta. Journal Of Management, Volume 2 No.2 , 4-12.

Rifiati, S., \& Rahadian, E. P. (2011). Persepsi Masyarakat Tentang Citra Kota Cimahi. Jurnal Unikom, 49-60.

Riduwan. (2013). Belajar Mudah Penelitian. Bandung: Alfabeta.

Siregar, I. S. (2012). Statistik Parametik Untuk Penelitian Kuantitatif. Jakarta: PT Bumi Aksara.

Siti, A. (2015). Peranan Strategi Promosi Pemasaran Terhadap Peningkatan Volume Penjualan. Jurnal Lentera, 43-58.

Sparks, B., Bowen, J., \& Klag, S. (2003). Restaurant And Tourist Market. Emerald Insight, 1-12.

Suartha. (2006). Manajemn Perhotelan. Kuta Utara: Mapindo.

Sugiyono. (2012). Memahami Penelitian Kuantitatif. Bandung: Alfabeta.

Sugiyono. (2014). Metedologi Penelitian Bisnis. Bandung: Alfabeta.

Sujatno, A. B. (2011). Hospitality: Secret Skill, Attitude And Performance For Restaurant Manager Eds. Pertama. Yogyakarta: Andi.

Sulyus, N. (2011). Event Organizer: Dasar- 
Dasar Event Management. Jakarta: Kompas Gramedia.

Sumarwan, U. (2011). Perilaku Konsumen: Teori Dan Penerapannya Dalam Pemasaran. Bogor: Ghalia Indonesia.

Susetyarsi, T. (2012). Membangun Brand Image Produk Melalui Promosi Event Sponsorship Dan Publisitas. Jurnal STIE Semarang .

Tiawarma, T. L., \& Rendy, I. (2013). Perancangan Media Promosi Pendukung Evrnt Sebagai Strategi Promosi Perusahaan Speaking Wall. VICIDI , 1-7.

Tobing, J (2016, Juni 06) Asus.Com. Retrieved Agustus 11, 2017, From Asus.Com: Asus: Www.Asus.Com/Zentalk/Id/Thread78296-1-/Html

Utama, I. B., \& Mahadewi, N. M. (2012). Metodologi Penelitian Pariwisata Dan Perhotelan. Yogyakarta: Andi Publisher.

W.A, M. (2005). Restoran Dan Segala Permasalahannya. Yogyakarta: Andi.

Wahyu, M. W. (2012). Analisis FaktorFaktor Yang Mempengaruhi Minat Beli Ulang Masyarakat Terhadap Produk Handphone. Jurnal Unimus Ac.Id Vol.8 No. 2 , 47-62.

Wanjat, K., Sri, M., \& Ghassani, F. (2016). Hubungan Daya Tarik Wisata Dengan Motivasi. Jurnal Manajemen Resort Dan Leisure Vo. 13 No. 1, 36-43.

Wildani, K. (2012). Hubungan Kebiasaan Minum Kopi Dan Merokok Dengan Hipertensi Pada Orang Dewasa Di Dusun Tambak Rejo Desa Gayaman Kecamatan Mojoanyar Mojokerto. Jurnal Poltekkes Majapahit, 1-12.

Wiratmoko, A. (2012). Pengaruh Kegiatan Ekstakulikuler Robotika Terhadap Kecerdasan Emosional Siswa Di SMKN 3 Yogyakarta. Eprints Uny, 8.

Wulanytha, U. (2015). Fungsi Promosi Dalam Meningkatkan Daya Beli Gadget Samsung Dikota Manado. EJournal Acta Diuma , 1-9.

Yusvin, O. S. (2016, April 18). Pemanfaatan
Media Sosial Instagram Sebagai

Wadah Pemasaran Yang Efektif. Retrieved September 2017, 27, From Sbm.Binus.Ac.Id:

Https://Sbm.Binus.Ac.Id/2016/04/18/

Pemanfaatan-Media-Sosial-

Instagram-Sebagai-Wadah-

Pemasaran-Yang-Efektif/

Zimry, R. M. (2013). Periklanan Dan Citra Merek Pengaruhnya Terhadap

Keputusan Pembelian Kendaraan Bermotor Yamaha. EMBA , 820-829.

Zulkifli Abd., L., \& Nur Ayuni, S. S. (2015).

New Business Set Up For Branding

Strategies On. Elsevier , 13-23. 